\section{Research Square \\ Preprints are preliminary reports that have not undergone peer review. \\ They should not be considered conclusive, used to inform clinical practice, or referenced by the media as validated information.}

\title{
Developing an Instrument to Assess Children's Capacity for Assent in Research Settings: Considering the Capacity of Five-year-olds in Japan
}

Izumi Ishiyama ( $\nabla$ izumi_ishiyama@yahoo.co.jp)

Tokoha University

\section{Kimiko Akama}

Shinshu Honan College

\section{Zentaro Yamagata}

University of Yamanashi

Izumi Ishiyama

Tokoha University

\section{Research Article}

Keywords: assent, capacity, consent, ethical guideline, instrument, research

Posted Date: May 10th, 2021

DOI: https://doi.org/10.21203/rs.3.rs-506179/v1

License: (c) (i) This work is licensed under a Creative Commons Attribution 4.0 International License. Read Full License 


\section{Abstract}

Background: When children are considered for research participation, international guidelines suggest that they should provide assent in addition to the consent of their parents or legally authorised representatives. Guidelines indicate that the assent-capable age of children, as a reference, is above seven years. However, previous studies that have clarified the appropriate age for assent are unavailable in Japan. If it can be shown that children under the age of seven have capacity for assent, it will clarify that assent is possible above the age of seven years. Therefore, we aimed to develop an instrument to assess children's capacity for assent among four- to six-year-olds and research their capacity for studies with no invasion or intervention.

Methods: To develop the instrument, we referenced a semi-structured interview instrument for assessing decision-making capacity to consent to participation in human subject research. Our instrument is composed of three sections based on 10 question items. Each answer is scored $0-2$, and the total score is in the range of $0-20$. Assent information was modified to be understood by four-year-olds in Japanese. To examine an instrument and to assess children's capacity for assent, we conducted a study with 68 participants, aged to four to six years. The scores were analysed using a factor analysis, reliability analysis, one-way analysis of variance, t-test, and $\chi 2$ test.

Results: The average age of participants was 5.4 years, the average interview time was 9.6 min, and the average scale score (range $0-20$ ) was $14.4 \pm 3.8$ points in total. Results showed a significant difference between four-year-olds and five-year-olds in the scale scores of assent capacity, largely attributable to differences in understanding and appreciation.

Conclusions: The reliability and validity of this scale was indicated as sufficient. For studies with no invasion or intervention, five-year-olds may have the capacity for assent if provided adequate information about the research, tailored to their level of maturity with a child-friendly assent process. However, it cannot be stated that five to six-year-olds fully understand the significance of participating in a study that includes potential benefits for someone other than themselves. Future research may consider comparing six and seven-year-olds or older children.

\section{Introduction}

Health-related research involving children is essential for advancing child health and wellbeing. ${ }^{1}$ Children must be included in the research unless a good scientific reason justifies their exclusion. As children have distinctive physiologies and health needs, they merit special consideration by researchers and research ethics committees. However, their distinctive physiologies and emotional development may also place children at increased risk of harm when conducting research. Moreover, without appropriate support, they may not be able to protect their own interests because of their evolving capacity. Specific protections to safeguard children's rights and welfare in research are therefore necessary. ${ }^{2}$

Current ethical principles for conducting research involving children have evolved from the Nuremberg Code, ${ }^{3}$ which emerged after the Second World War, and notably included a bar on research involving children. Research has been seen as a potential harm from which vulnerable people should be protected. Later, in 1964, the Declaration of Helsinki ${ }^{4}$ advised that research involving minors could be carried out where the research is necessary to promote the health of the population represented and cannot otherwise be performed on legally competent persons. The US Department of Health, Education, and Welfare issued guidelines that were codified into the Federal Regulations 45 CFR 46 in $1974 .^{5}$

The US National Commission for the Protection of Human Subjects of Biomedical and Behavioral Research laid down ethical principles and guidelines for the protection of human subjects of research. In their report, 'Respect for Persons' is mentioned as the first of three basic ethical principles. Informed consent is described as containing three elements: information, comprehension, and voluntariness. It is noted that information generally includes the following items: the research procedure, its purpose, risks, anticipated benefits, and a statement offering the subject the opportunity to ask questions and withdraw at any time from the research. ${ }^{6}$ This report had a major impact on subsequent research ethics.

In 1995, the American Academy of Pediatrics (AAP) stated in its application to paediatric practice:

Only patients who have appropriate decisional capacity and legal empowerment can give their informed consent to medical care. In all other situations, parents or other surrogates provide informed permission for diagnosis and treatment of children with the assent of the child whenever appropriate... in most cases, physicians have an ethical (and legal) obligation to obtain parental permission to undertake recommended medical interventions. In many circumstances, physicians should also solicit a patient assent when developmentally appropriate. ${ }^{7}$

This description includes consideration of children's developing capacities for participating in decision-making and indicates that a child's consent consists of parental permission and the child's own assent.

The World Medical Association (WMA) 52nd General Assembly 2000 amended the Declaration of Helsinki, stating:

Page 2/11 
When a subject deemed legally incompetent, such as a minor child, is able to give assent to decisions about participation in research, the investigator must obtain that assent in addition to the consent of the legally authorised representative. The potential subject's dissent should be respected (WMA, 2000). ${ }^{4}$

From this declaration, the term 'assent' might be recognised internationally by health-related research investigators.

Presently, one of the most acceptable definitions is 'Assent means a child's affirmative agreement to participate in research. Mere failure to object should not, absent affirmative agreement, be construed as assent'. ${ }^{5}$ Another similar accepted definition was provided by the WHO:

A variation on consent where a person who does not possess full competence to give informed consent gives affirmative agreement to participate in research. However, it is important to note that assent does not eliminate the need to obtain permission from a parent or other legally authorised decision-maker. ${ }^{8}$

Concerning the quality of information for children, the Ethics Working Group of the Confederation of European Specialists in Paediatrics mentions that all information, including language and drawings, should conform to the child's capacity to understand. ${ }^{8}$ The group states that the content of information that needs to be provided to the children and their guardians should include the following:

1. What is going to be done?

2. Why is it going to be done?

3. What is the intended outcome?

4. What are the benefits and risks of the treatment proposed?

5. What are the alternatives, including benefits and risks?

6 . What will happen if nothing is done?

In relation to the capacity of children, the Medical Research Council (MRC) described in their Ethics Guide:

...competence of a child is considered not to depend primarily on age, but rather on the ability to understand and weigh up options. It can be influenced by the way information is presented-many children will be competent if information is presented in an appropriate way and they are supported through the decision-making process. ${ }^{1}$

In the case of children deemed incompetent to consent to participate in research, if the child is able to give assent, the investigator must obtain that assent in addition to the consent of the legally authorised representative, and if the child does not assent, this should be respected.

The current conception of a child's assent is included in international ethical guidelines for health-related research involving humans. ${ }^{2}$ The items to be noted are summarised as follows:

1. Children who are legally minors cannot give legally valid informed consent, but they may be able to give assent.

2. To give assent means that the child is meaningfully engaged in the research discussion in accordance with his or her capacities.

3. Assent must be considered as a process and not merely the absence of dissent.

4. The researcher must involve the child in the actual decision-making process and use age-appropriate information.

5. It is of major importance to inform the child and obtain assent as described above, preferably in writing for children who are literate.

6. The process of obtaining assent must take into account not only the age of children but also their individual circumstances, life experiences, emotional and psychological maturity, intellectual capabilities, and family situation.

7. In general, a deliberate objection by a child to participate in research must be respected, even if the parents have given permission, save in exceptional circumstances.

8. In this case, the parents' decision must be overridden if the researcher believes it is not in the child's best clinical interest to enrol or continue study participation.

9. If children reach the legal age of maturity during the research, their consent to continue participation should be obtained.

10. Before undertaking research, the researcher and the research ethics committee must ensure that the child's assent has been obtained in keeping with the child's capacity, after having been provided with adequate information tailored to the child's level of maturity.

As mentioned in point 10 above, the adjudication concerning capacity is the responsibility of the researcher and the research ethics committee; thus, they must address the real issues and questions regarding the age at which to seek assent and how to measure the child's capacity.

Previous studies indicate that assent from children as young as seven years for medical interventions may help them become more involved in 
their medical care and foster moral growth and the development of autonomy in young patients. ${ }^{7,10}$ However, as mentioned in point six above, researchers must take into account the child's individual circumstances, intellectual capabilities, and so on.

Cheah and Parker ${ }^{11}$ note that the concept of assent in the current guidelines is confusing, and there is an urgent need for the development of clearer guidelines that can be adapted for all types of paediatric research. They argue that there is a pressing need for further empirical work and ethical analysis in this important area. Weisleder ${ }^{12}$ also indicates that, based on a systematic review, the challenge is that empirical data supporting researchers' use is limited. Oulton et al. argue the following:

The debate about assent needs to move away from terminology, definition and legal issues. It should focus instead on practical ways of supporting researchers to work in partnership with children, thus ensuring a more informed, voluntary, and more robust and longer-lasting commitment to research. ${ }^{13}$

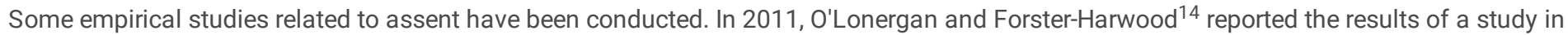
which they combined visual and audio media to improve the comprehension of the process of assent. The authors suggest that multimedia approaches may improve the overall understanding of research participation for children and parents, and the approach is particularly wellsuited for the assent process. Annett et al. ${ }^{15}$ consider that minors cannot dissent under social pressure, and seeking assent from minors separate from their parents would be a more meaningful exercise. When families were randomly assigned to remain together or separated during a consent/assent process, results showed that the separate procedure improved knowledge of study risks and benefits for older adolescents and their parents. Massetti et al. ${ }^{16}$ developed a comic book created to facilitate children's understanding of what constitutes informed assent with clear and simple language. Twenty children between 7 and 12 years of age were enrolled in the study, and most of the participants answered that they perceived the content of the text to be excellent or very good. Researchers concluded that the construction of a simple and clear model of informed assent is possible, and this model should be used in experiments with children.

In Japan, the Ministry of Health, Labour, and Welfare (MHLW) and the Ministry of Education, Culture, Sports, Science and Technology (MEXT) ${ }^{17}$ have declared the Ethical Guidelines for Medical and Health Research Involving Human Subjects, which indicate the assent-capable age of children, as a reference, as above seven years. However, previous studies that clarified the appropriate age are not available in Japan. Therefore, we aimed to first research and then develop a measure to assess children's capacity for assent. If our study shows that assent is possible in children under the age of seven, it becomes clear that assent is possible above the age of seven years. In this study, we sought to conduct a study with no invasion or intervention, which is the first of many kinds of studies we intend to carry out in our research on children's assent.

To develop a measure for assessing children's capacity for assent, we referenced the MacArthur competence assessment tool for clinical research (MacCAT-CR) ${ }^{18}$, a semi-structured interview instrument for assessing decision-making capacity to consent to participation in human subject research. It is composed of four sections: understanding, appreciation, reasoning, and 'expressing a choice'. Based on a review of instruments, Dunn et al. ${ }^{19}$ stated that the MacCAT-CR was the best competence assessment tool for adults among the available tools. In a previous study, Hein et al. ${ }^{2}$ used the MacCAT-CR to assess 6- to 18-year-old children's competence to consent, and clarified years of age as the factor that explains most of the variance in children's competence to consent, followed by intelligence. We intended to assess four- to six-yearold children's capacity to assent using a modified MacCAT-CR to make it applicable to late childhood.

We selected children aged four to six years as the study subjects with reference to the composition of Wechsler Preschool and Primary Scale of Intelligence-Third Edition ${ }^{21}$ (WPPSI-III), a personalised clinical test that measures the intellectual abilities of infants. The test consists of two parts, two years six months to three years 11 months, and four years zero months to seven years three months, considering the volatility of cognitive development in young children. According to the Japanese version of the WPPSI-III: Technical and Interpretative Manual, dividing the age range by four years is based on empirical evidence and practical needs. Subtest batteries over the age of four include the formation of language concepts, abstract reasoning, and fluidity reasoning. From this, it was speculated that children over the age of four might be able to answer questions for measuring assent capacity. In addition, since children over the age of seven have reached school age, it is estimated that they might have assent capacity under various ethical guidelines. This study focused on developing an instrument to measure the capacities of preschool age children.

The aims of this study were to develop an instrument to assess children's capacity for assent and to compare the capacity for assent among four- to six-year-olds. We sought assent from the children for a study with no invasion or intervention.

\section{Methods}

\section{Participants}


From March 2019 to February 2020, 68 children aged four to six years participated in the study. The children's guardians had been informed by researchers about the study in which their children would participate, via oral and written communication, and they had given consent (in other words, permission). The three surveys were conducted at one regional childcare support base (in March 2019 on 27 children), one childcare support centre (in August 2019 on 26 children), and one kindergarten (in February 2020 on 15 children).

\section{Interview method}

We conducted separate sessions consisting of two interviews for each child in a private room. The first interview aimed to assess the capacity of the assent. In the first interview, a researcher, using an illustrated booklet (Figure 1), gave the child a clear explanation tailored to the child's level of maturity about a study that was going to be carried out with no invasion or intervention (the second structured interview resilience scale survey). The explanatory booklet includes information on (1) the research plan, (2) aim, (3) potential risks and benefits, (4) voluntary participation, and (5) contact information, referenced to Levy et al.'s Statement of CESP. ${ }^{9}$

After the explanation, the interviews were assessed using a scale (Table 1). The researcher prompted and answered the child's questions. The child was asked to say what they had understood in their own words. In this process, the researcher recorded the words and scored eight items in the 'Understanding \& Appreciation' section. If the child failed to speak spontaneously, more specific confirmation questions were asked according to the scenarios. The answers were recorded and scored. The 'Expressing a Choice' section and the 'Reasoning \& Consistency' section proceeded in the same way according to the scenarios.

\section{Development of assessment scale}

The assessment scale is composed of a semi-structured interview guide and a record form based on MacCAT-CR. The original MacCAT-CR comprises four sections. Our revised scale collapses these categories into three sections, taking into account the children's ages, life experiences, emotional and psychological maturity, and intellectual capabilities. We modified the language to be understood by four-year-olds by referring to the 'New Version K-type Development Test' in Japanese, a test designed to capture the status of infant development across aspects of mental activity. ${ }^{22}$ Concerning the scores (range: $0-2$ ), we analysed the captured image reactions of children taken in the pilot study conducted in October 2016. Three reaction patterns were extracted and scored: 'answered in own words' (score: 2), 'nodded clearly to additional explanations' (score: 1), and 'did not respond clearly' (score: 0). We named the scale 'Instrument to Assess Children's Capacity for Assent'.

When a child gave assent to participate in future research, they were asked for a signature or to draw a mark on the assent form (Figure 2). When the child expressed a deliberate objection, we halted the research. When the child at first gave assent but wanted to withdraw the assent later during the study, they were asked for a signature or mark on the assent withdrawal form (Figure 3) and were released from the study.

Researchers measured the time consumed in the process of acquiring assent from each child and recorded details of the child's responses, attitudes, and the scores of each item in the three sections. The researchers referred to paper records of the interview sessions while discussing the assessment of assent capacity.

\section{Reliability and validity of this scale}

To examine context validity, the questionnaires were developed with assistance from clinical psychologists, speech therapists, and researchers on child development.

To examine construct validity, we performed a factor analysis of ten items on the scoring date of the 68 children who participated in the research. The results of the maximum-likelihood method factor analysis with Promax rotation are presented in Table 2 . Three factors were extracted by analysing all ten items without excluding any items. The first factor consisted of five items and included items related to the 'Understanding and Appreciation' section about the research plan and the aim of the research. Therefore, it was named as the 'Understanding and Appreciation of Aim and Research Plan' factor. The second factor is composed of three items: 'Do you think the questions will be fun?', 'Must you take part?', and 'Is it okay to stop participating at any time?'. Therefore, we named it the 'Understanding of Voluntary Participation' factor. The third factor consisted of two items: expressing choice and reasoning and consistency items. Therefore, we named it the 'Expressing a Choice with Reasoning and Consistency' factor. As a result of the analysis, it became clear that this scale is composed of the elements necessary for assent, such as understanding and appreciation of aim and research plan, understanding of voluntary participation, and expressing a choice with reasoning and consistency. It could be said that the entire questionnaire measures what it intends to do. Therefore, this scale has construct validity.

Reliability analysis was performed for all ten items on the scoring date of 68 children who participated in the research, and the Cronbach'sawas .852. Results indicated that this measurement had sufficient internal consistency. 
The scores were analysed by age group using one-way analysis of variance (ANOVA), $t$-test, and $\chi^{2}$ test. All analyses were performed using the SPSS version 22. Differences were considered significant at $p<0.05$ (two-sided test).

\section{Review and revision}

All the research methods were reviewed and revised through a pilot study conducted in October 2016 on 18 children with the cooperation of the Institute for Learning and Development. Ethical considerations for this research followed the CIOMS guidelines. ${ }^{2}$ This study was approved by the Tokoha University Research Ethics Committee.

All studies were conducted in Japanese. The data were originally collected in Japanese and translated into English by the first author at the time of writing this paper.

\section{Results}

The results of the participants' characteristics and responses to the scale are shown in Table 3. The average age was 5.4 years. Regarding the interview style of separate assent sessions, $95.6 \%$ of participants came to the interview alone, and three participants aged four years came with a guardian. Among the three participants, one child expressed assent to participate in future research with a total score of 13 points, one child expressed dissent with a total score of seven points, and one child expressed nothing with a total score of zero. Further, $94.1 \%$ of participants agreed to participate in the second structured interview resilience scale survey. Two expressed clear dissent, but two showed neither an attitude of assent nor dissent. The $\chi^{2}$ test showed no significant differences among the three age groups. All participants who assented to the second interview (100\%) wrote signs or marks on the assent form. However, there was an age group difference in writing style on the assent form ( $p$ $<0.05$ ). The number of participants who signed their forms increased with age. The average interview time was 9.6 min, and one-way ANOVA showed no significant difference in interview length by age group. The average scale score (range $0-20$ ) was $14.4 \pm 3.8$ points in total. One-way ANOVA showed no significant difference in scores by age group, although the t-test showed a significant difference between the four- and fiveyear age groups $(p<0.01)$. The difference between the five- and six-year age groups was not significant.

Table 4 shows the scale scores of the three capacity sections analysed by age group. One-way ANOVA showed no significant differences according to age group. Similar to the total score, the 'Understanding \& Appreciation' section (range 0-16) t-test showed a significant difference between the four and five-year age groups $(p<0.01)$. The difference between the five and six-year age groups was not significant.

Table 5 shows the detailed score of 'Understanding \& Appreciation' analysed by age group. One-way ANOVA showed no significant differences according to age group. The t-test showed a significant difference between the four and five-year age groups in three items $(p<0.01)$ and two items $(p<0.05)$. In 'possible withdrawal' items, the difference between the three age groups was not significant.

In the 'Understanding \& Appreciation' section, the question 'How would it be useful if you answer the questions?' was the item that most commonly received a zero score among the eight items. A total of $33.3 \%$ of 4 -year-olds, $12.0 \%$ of 5 -year-olds, and $10.5 \%$ of 6 -year-olds scored 0 points. Participants with 0 points did not respond clearly; they neither answered in their own words, nor did they clearly nod or shake their head at additional explanations. This question asked whether they understood the essential significance of participating in the study, which queries the understanding of the meaning of a study that includes potential benefits for someone other than themselves.

\section{Discussion}

To develop an instrument to assess children's capacity for assent, we created a study with no invasion or intervention and interviewed 68 children using the instrument. We compared the capacity for assent of four to six-year-old children by age group.

The information, language, explanatory booklet, the instrument composed of a semi-structured interview guide and a record form, scoring, assent form, and assent withdrawal form were all tailored to the child's level of maturity and adapted to the requirements of the current study.

It was found that there is a significant difference between children aged four and five years in capacity for assent. This difference was largely recorded in the 'Understanding \& Appreciation' section. In contrast, there was no significant difference between the five- and six-year-olds in all sections. In the case of studies consisting of a structured interview resilience scale survey with no invasion or intervention, it is suggested that five-year-olds might have the capacity for assent. It was also found that age might be a factor affecting assent capacity. This finding supports Hein et al.'s ${ }^{20}$ suggestion that age is a factor in explaining children's competence to consent, although there is a conceptual difference between consent and assent.

In the 'Understanding \& Appreciation' section, the question of whether they understood the essential significance of participating in the study was the item that received the most 0 points among five- and six-year-olds. It could not be stated that the five- and six-year-olds fully understood 
the significance of participating in the study. It is necessary to consider the age at which the significance of participating in the research can be understood by comparing it to children aged seven years or older in future studies.

The fact that $94.1 \%$ of participants gave assent to take part in future research and $100 \%$ of them wrote a sign or drew a mark on the assent form pointed to the positive impact of explanation using an illustrated booklet. This result supports Massetti et al.'s ${ }^{15}$ report, which describes the development of a comic book created to facilitate children's understanding of informed assent with clear and simple language.

Regarding separate assent sessions, two of the three participants who came for the interview with a guardian were assumed to have a lower understanding of the future study. Comparing the average scale score of their age, $11.9 \pm 4.1$ points, two out of the three were below it. A child's social maturity, reflected in the ability to separate from a guardian during the assent process, might indicate the child's active participation or decision-making capacity. As Annett et al. ${ }^{15}$ stated, an autonomy-enhanced assent procedure, conducted without parental intervention, would improve children's assent by increasing their knowledge and willingness to participate.

The UK National Research Ethics Service provides information sheets and consent forms for children. ${ }^{23}$ There are different information sheets designed for different age ranges; for example, ages 11-15 years, ages 6-10 years, and children aged five years and under. The value of such sheets is uncertain, and the practice of providing written information to younger children may be pointless. Parents must provide consent. The information sheets include a checklist with 'Yes/No' answers. Example questions include: 'Do you understand what this project is about?', 'Have you asked all the questions you wanted?' and Are you happy to participate? Compared to these forms, our instrument is more child-friendly; it is tailored for children four years and above to reflect their comprehension and development. Further, it is designed to deepen children's understanding through dialogue while asking detailed questions.

Regarding the reliability and validity of this scale, the context validity was confirmed by experts in the process of its development. We performed a factor analysis using all the question items and the results showed that this scale is composed of the elements necessary for assent; thus, this scale can be said to have construct validity. Reliability analysis was performed, and the Cronbach's a indicated that this measurement has sufficient internal consistency. These analyses suggest that this instrument for assessing children's capacity for assent was appropriately developed and might be recommended for practical use in the field of young children's research.

However, in order to further improve its practicality, our instrument needs to be validated using more samples. In the instrument, question items which many participants could not answer using their own words were in the 'Aim, Risk, and Benefit' section. The lowest scores were for the two questions: 'So, how would you answer the questions?' and 'How would it be useful if you answered the questions?' For the participants, 'how' questions are the difficult ones to answer using their own words. In contrast, participants tended to give clear answers to the questions that could be answered with 'Yes' or 'No'. Using this instrument as a base, further study is required to strengthen validity and reliability, with the aim of developing an adequate assent-capacity scale for children.

As Weisleder ${ }^{12}$ mentions, adults are deemed to have decision-making capacity unless researchers have reasons to believe otherwise, while in the case of children, the assumption is reversed-they are presumed to lack decision-making capacity until proven otherwise. Weisleder ${ }^{12}$ describes unconscious bias; for example, researchers tend to judge a child to have decision-making capacity if the child's decision to assent conforms to their own ideas of what is in the child's best interest. Conversely, if the child seems to make the wrong decision, adults take it upon themselves to guide the decision-making process to ensure that the child makes the right decision. The Committee on Bioethics states that despite the long-standing stance of the AAP, there is still no widespread understanding and endorsement among practitioners concerning the concept of paediatric assent or refusal. ${ }^{6}$

When nested within the requirement for parental permission, child assent functions as a means to promote children's moral growth and development of autonomy, rather than as an autonomous decision. ${ }^{23}$ Following an assent process tailored for the target age might lead to research with children who are involved as active participants. Based on our research, we present a revised example of the assent-capacity measurement scale.

\section{Limitations}

To strengthen the instrument's validity and reliability, it needs to be validated using more samples. In the tool, the lowest scores were found for the following two questions: 'So, how would you answer the questions?' and 'How would it be useful if you answered the questions?' For the participants, 'how' questions are difficult to answer using their own words. These questions require further correction to develop a more appropriate assent-capacity scale for children.

It cannot be stated that the five- and six-year-olds fully understood the essential significance of participating in a study that includes potential benefits for someone other than themselves. A comparison between children aged six and seven years or older could explore differences in participants' understanding of the meaning of research participation.

Page $7 / 11$ 


\section{Conclusion}

When children are considered for participation in research, international guidelines suggest that they should provide assent in addition to their parents' or legally authorised representatives' consent. To develop an instrument to assess children's capacity for assent, we conducted a study with 68 participants aged 4-6 years. Analyses revealed that this instrument has context validity, construct validity, and sufficient internal consistency. It was found that there is a significant difference between four-year-olds and five-year-olds in the assent-capacity scale scores. This difference is largely due to the differences in understanding and appreciation. It is suggested that five-year-olds might have the capacity to assent if they are provided adequate information about the research tailored to their level of maturity and undergo a child-friendly assent process. However, it could not be stated that the five- and six-year-olds fully understood the significance of participating in a study that includes potential benefits for someone other than themselves. A comparison between children aged six and seven years or older could be a topic for future research.

\section{Abbreviations}

MacCAT-CR: MacArthur competence assessment tool for clinical research

WPPSI-III: Wechsler Preschool and Primary Scale of Intelligence-Third Edition

\section{Declarations}

\section{Ethics approvaland consent for publication}

The children's guardians were informed by researchers about the study in which their children would participate via oral and written communication, and they provided consent (in other words, permission).

This study was approved by the Tokoha University Research Ethics Committee.

\section{Consent for publication}

Not applicable

\section{Availability of data and materials}

The datasets used and/or analysed during the current study are available from the corresponding author on reasonable request.

\section{Competing interests}

The authors declare that they have no competing interests.

\section{Funding}

This work was supported by JSPS KAKENHI, Grant-in-Aid for Scientific Research (C), Grant Numbers 17 K01922 and 25500012.

\section{Authors' contributions}

I I made substantial contributions to the conception and design of the research. She worked on the acquisition and analysis of the data. K A contributed to determine the context validity of the instrument and developed a child-friendly method for the research. $Z \mathrm{Y}$ drafted the paper and revised the research for more practical use. All authors read and approved the final manuscript.

\section{Acknowledgements}

We are grateful to Toshio Minami (Ryukoku Kindergarten), Kaori Naito (Child Care Support Centre Chibikko-House), Masumi Shinohara (Child Care Support Centre Nirachibi), and Taeko Karube (Regional Child Care Support Base Anfannet) for their thoughtful and kind research cooperation. We would also like to thank all the study participants, children, and their guardians for their time and sincere efforts.

We would like to thank Editage (www.editage.com) for English language editing.

\section{References}

1. Medical Research Council. MRC ethics guide medical research involving children. 2004. https://mrc.ukri.org/documents/pdf/medicalresearch-involving-children. Accessed 3 Apr 2021. 
2. Council for International Organizations of Medical Sciences (CIOMS) and World Health Organization (WHO). International ethical guidelines for health-related research involving humans. 2016. https://cioms.ch/wp-content/uploads/2017/01/WEB-CIOMSEthicalGuidelines.pdf. Accessed 3 Apr 2021.

3. The Nuremberg Code. Trials of War Criminals before the Nuremberg Military Tribunals under Control Council Law No. 10. 2;181-182. Washington DC, US Government Printing Office; 1947. https://history.nih.gov/research/downloads/nuremberg.pdf.

4. World Medical Association (WMA). Declaration of Helsinki: Ethical principles for medical research involving human subjects. 1964. https://www.wma.net/policies-post/wma-declaration-of-helsinki-ethical-principles-for-medical-research-involving-human-subjects/.

5. Office for Human Research Protections. Code of federal regulations, 45 CFR 46. https://www.hhs.gov/ohrp/regulations-andpolicy/regulations/45-cfr-46/index.html. Accessed 3 Apr 2021.

6. National Commission for the Protection of Human Subjects of Biomedical and Behavioural Research. The Belmont report: Ethical principles and guidelines for the protection of human subjects of research. 1979. https://www.hhs.gov/ohrp/regulations-andpolicy/belmont-report/read-the-belmont-report/index.html. Accessed 3 Apr 2021.

7. American Academy of Pediatrics (Committee on Bioethics). Informed consent, parental permission, and assent in pediatric practice. 1995;95(2):314-317.

8. World Health Organization. Research ethics committees: Basic concepts for capacity-building. 2009. https://apps.who.int/iris/bitstream/handle/10665/44108/9789241598002_eng.pdf. Accessed 3 Apr 2021.

9. Levy, MD, Larcher, V, Kurz, R. Informed consent/assent in children: Statement of the Ethics Working Group of the Confederation of European Specialists in Paediatrics (CESP). European Journal of Pediatrics. 2003;162(9):629-633.

10. Katz, AL, Webb, SA, and Committee on Bioethics. Informed consent in decision-making in pediatric practice. Pediatrics. 2016;138(2), e20161485.

11. Cheah, PY, Parker, M. Consent and assent in paediatric research in low-income settings. BMC Medical Ethics. $2014 ; 15(1): 22$.

12. Weisleder, P. Helping them decide: A scoping review of interventions used to help minors understand the concept and process of assent. Frontiers in Pediatrics. 2020;8:25.

13. Oulton, K, Gibson, F, Sell, D, Williams, A, Pratt, L, Wray, J. Assent for children's participation in research: Why it matters and making it meaningful. Child Care, Health and Development. 2016;42(4):588-597.

14. O'Lonergan, TA, Forster-Harwood, JE. Novel approach to parental permission and child assent for research: improving comprehension. Pediatrics. 2011;127(5):917-924.

15. Annett, RD, Brody, JL, Scherer, DG, Turner, CW, Dalen, J, Raissy H. A randomized study of a method for optimizing adolescent assent to biomedical research. AJOB Empirical Bioethics. 2017;8(3):189-197.

16. Massetti, T, Crocetta, B, Guarnieri, R, Silva, TDD, Leal, AF, Voos, MC, Monteiro, CBD. A didactic approach to presenting verbal and visual information to children participating in research protocols: the comic book informed assent. Clinics. $2018 ; 73$.

17. Ministry of Health, Labour, and Welfare (MHLW) and Ministry of Education, Culture, Sports, Science and Technology (MEXT). Ethical guidelines for medical and health research involving human subjects. 2015. https://www.mhlw.go.jp/file/06-Seisakujouhou-10600000Daijinkanboukouseikagakuka/0000080278.pdf. Accessed 3 Apr 2021.

18. Appelbaum, PS, Grisso, T. MacArthur competence assessment tool for clinical research (MacCAT-CR). Sarasota: Professional Resource Press; 2001.

19. Dunn, LB, Nowrangi, MA, Palmer, BW, Jeste, DV, Saks, ER. Assessing decisional capacity for clinical research or treatment: a review of instruments. American Journal of Psychiatry. 2006;163(8):1323-1334.

20. Hein, IM Troost, PW Lindeboom, R, Benninga, MA, Zwaan, ZM, Van Goudoever, JB, Lindauer, RJ. Key factors in children's competence to consent to clinical research. BMC Medical Ethics. 2015;16(1):74.

21. Japanese version WPPSI-III Publishing Committee, Dairoku,K, Watanabe,Y. Japanese version of the WPPSI-III: Technical and interpretative manual. Tokyo: Japan Cultural Science Company; 2017. p. 9-10. (Original author) Wechsler, D. (Original publisher) Pearson; 2002.

22. Kyoto International Social Welfare Exchange Center. New version K-type development test. 2001. http://www.kiswec.com/inspection_01/. Accessed 3 Apr 2021.

23. UK National Research Ethics Service. Guidance for Researchers and Reviewers: Information Sheets and Consent Forms. 2011. https://www.Iscft.nhs.uk/media/Publications/R_and_D/Guidance/Template\%20Consent\%20Forms\%20and\%20Information\%20Sheets.pdf. Accessed 3 Apr 2021.

24. Miller, VA, Nelson, RM. A developmental approach to child assent for nontherapeutic research. The Journal of Pediatrics. 2006;149(1):S25S30.

\section{Tables}

Page 9/11 


\section{Figures}

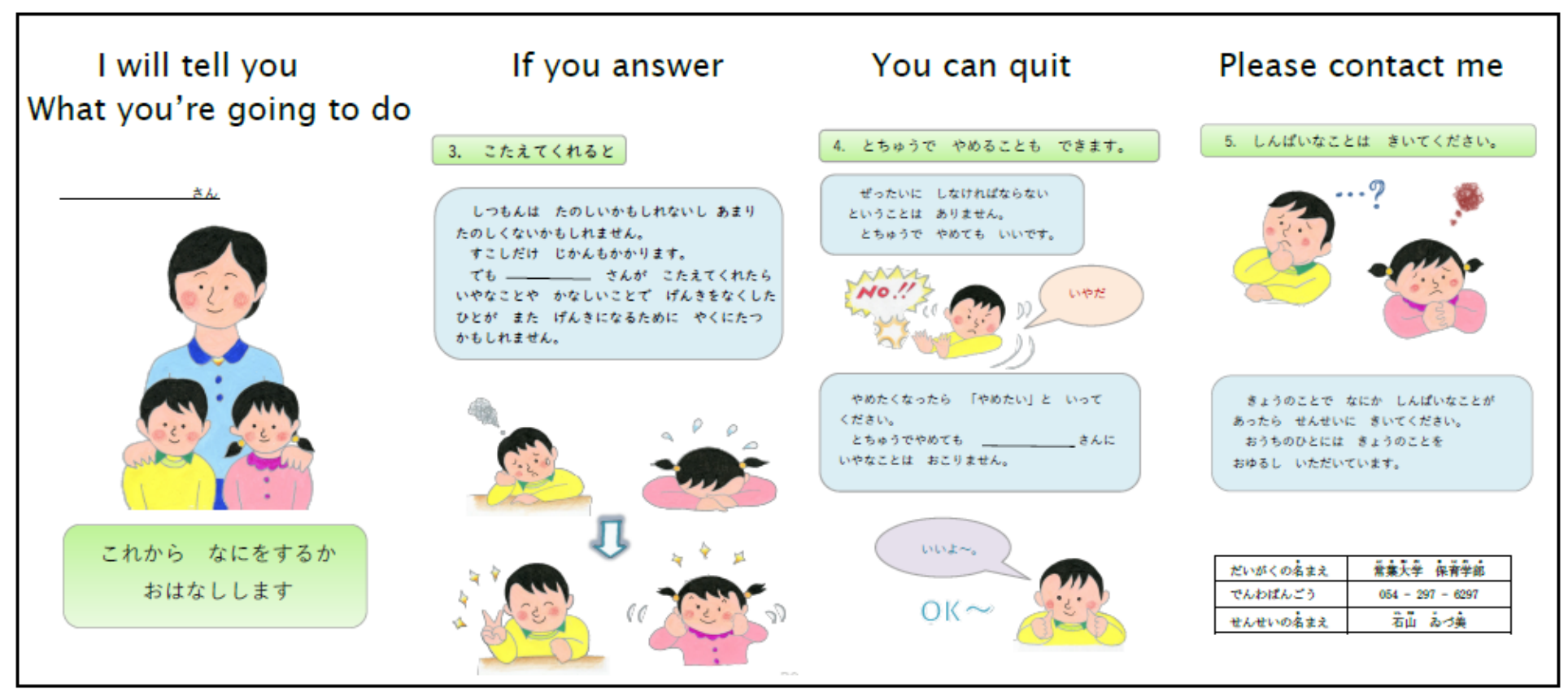

Figure 1

Explanatory booklet(abstract)

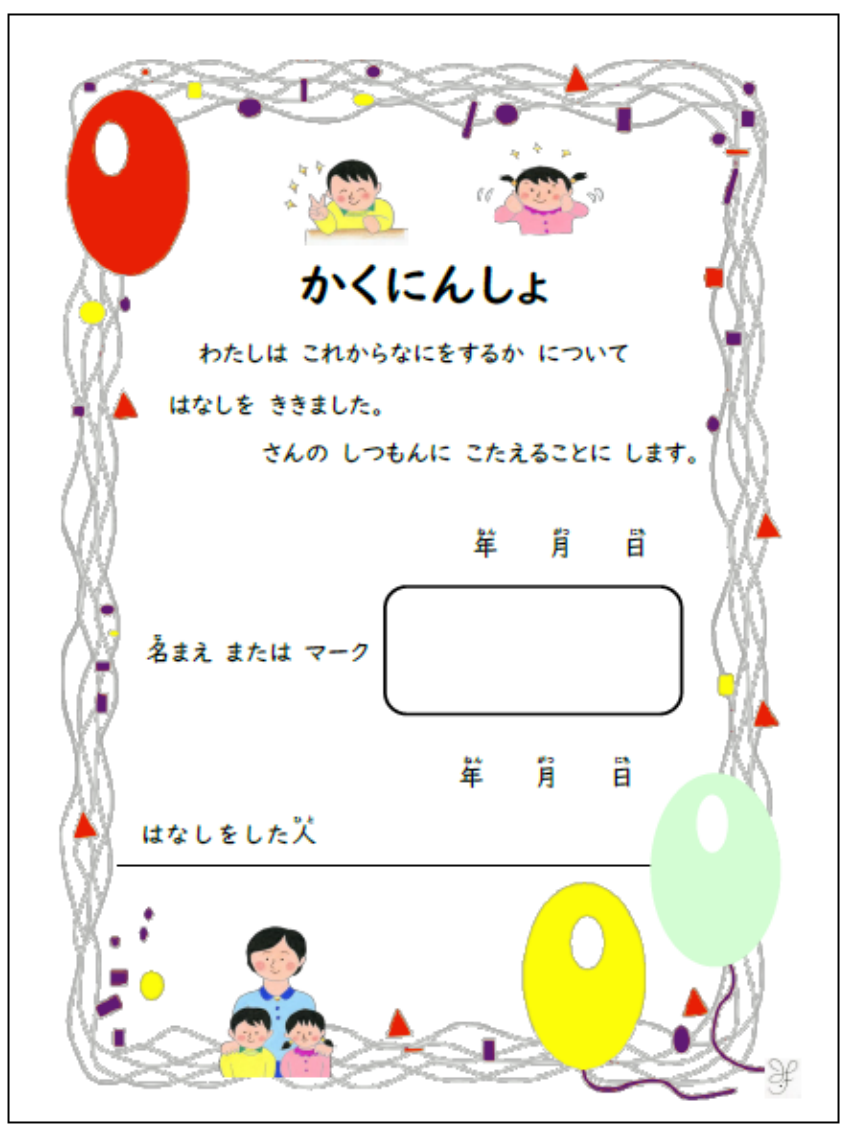

Figure 2 


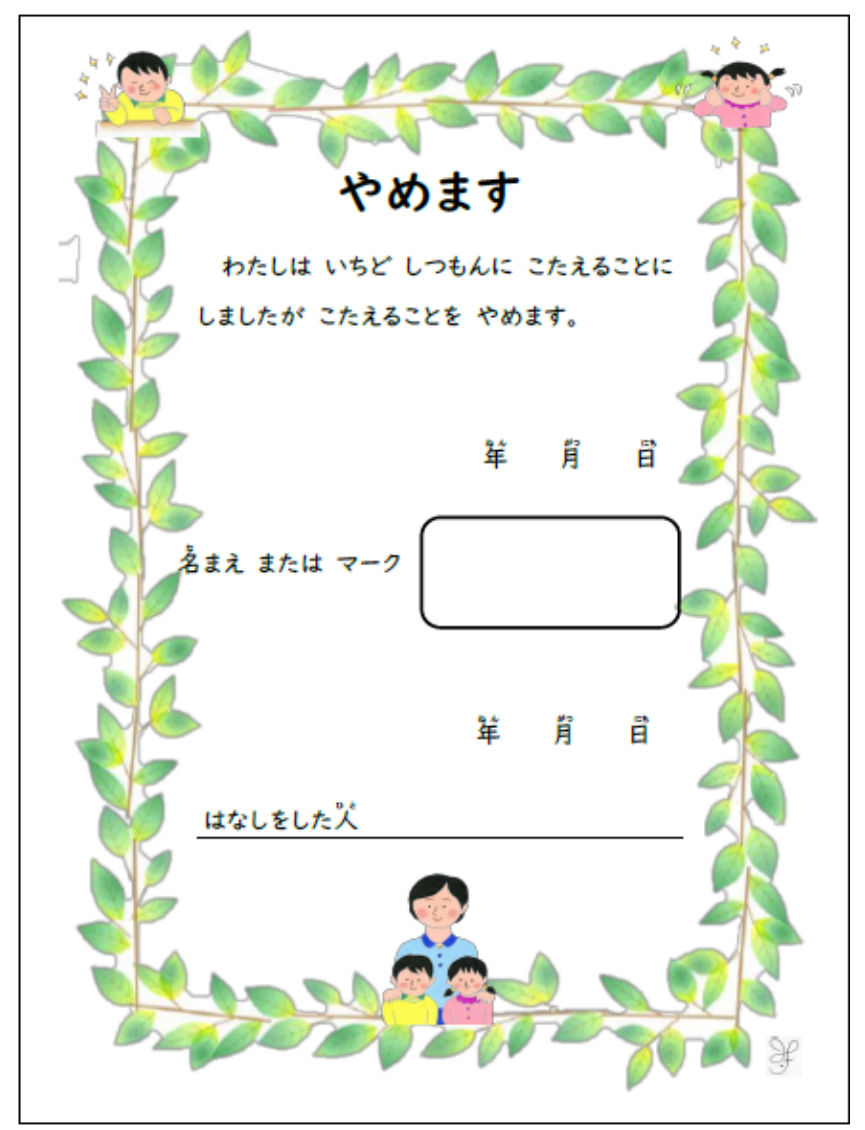

Figure 3

Assent withdrawal form

\section{Supplementary Files}

This is a list of supplementary files associated with this preprint. Click to download.

- 210508IshiyamaTable1.xIsx

- 210508IshiyamaTable2.xIsx

- 210508IshiyamaTable3.xlsx

- 210508IshiyamaTable4.xIsx

- 210508IshiyamaTable5.xIsx 